\title{
Gymnastics Athletes Hamstring Muscles Elasticity and Trunk Mobility
}

\author{
Enrika Baltrimaviciute and Kristina Zaicenkoviene* \\ Department of Trainings, Lithuanian Sports University, Lithuania
}

*Corresponding author: Kristina Zaicenkoviene, Department of Trainings, Lithuanian Sports University, Lithuania

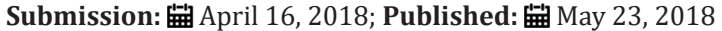

\begin{abstract}
Summary
Pilates exercise is popular in the general population [1] the clinical and fitness areas (Segal, 2004). The use of the Pilates at least at the end of training to improve dancers flexibility and trunk mobility was suggested [2]. Flexibility and joints mobility as well as core strengthening is the focal point of the Pilates exercises [3]. Hamstrimg muscle elasticity is important in many functional and athletic activities, because dancers must show high amplitude movements with lower extremities and trunk [3]. Aerobic Gymnastics athletes continuously perform complex movements following music patterns, which require high levels of fitness, strength, flexibility and range of motion in joins [4]. In spite of a growth in gymnastic modalities, we didn't find research about Pilates effect to young age Aerobic Gymnastics athletes. The aim of this study was to evaluate changes in Aerobic Gymnastics athletes hamstrings muscles elasticity and trunk mobility after 7 and 14 weeks of Pilates exercises.
\end{abstract}

Keywords: Pilates; Aerobic gymnastics; Trunk mobility; Hamstrings muscles elasticity

\section{Introduction}

The aim of research: to evaluate the effect of Pilates exercises on the 10-14 years old aerobic gymnastics athletes hamstring muscles elasticity and trunk mobility.

Object of research: 10-14 years old aerobic gymnastics athletes hamstring muscles elasticity and trunk mobility

Methods of research: literature review, anthropometric measurements, Hamstring muscles elasticity, Maximal Hip Flexion Active Knee Extension (MHFAKE) Test, measured with goniometer (Orthopedic Equipment Co., Bourbon, USA), Sit and reach test was measured with specialized box testing, For trunk flexion and extension was used two inclinometers, and for lateral flexion to right and left was used one inclinometer.

\section{Table 1:}

\begin{tabular}{|c|c|c|c|c|c|}
\hline Gr. & Subjects & Age(Years) & Height(m) & Weight(Kg) & KMI \\
\hline I & $\mathrm{n}=17$ & $12,24 \pm 1,26$ & $1,59 \pm 1,08$ & $45,25 \pm 4,65$ & $17,93 \pm 1,22$ \\
\hline II & $\mathrm{n}=16$ & $12,19 \pm 1,08$ & $1,57 \pm 1.04$ & $44,69 \pm 4,31$ & $17,99 \pm 0,85$ \\
\hline
\end{tabular}

Mathematical statistical analysis: In research participated 33 Aerobic Gymnastics athletes (Table 1). They were divided in to II groups: I-they attend aerobic gymnastic training and did mat Pilates exercises (experimental), II-control, attend only aerobic gymnastic training (control) (Figure 1).

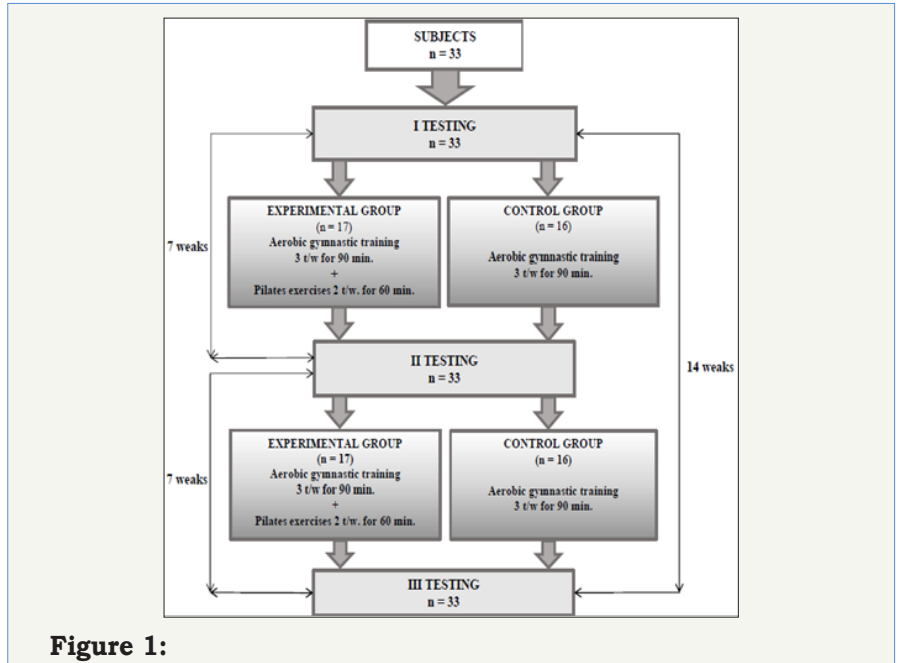

Hypothesis: We hypothesize that Pilate's exercises will improve 10-14 years old aerobic gymnastics athletes' hamstring muscles elasticity and trunk mobility.

\section{Objectives of Research}

1. To evaluate and compare aerobic gymnastics athletes hamstrings muscles elasticity before and after the Pilates exercises application.

2. To evaluate and compare aerobic gymnastics athletes trunk mobility before and after the Pilates exercises application. 
3. Compare obtain results before and after the Pilates exercises application with control group which Pilates exercises was not applied.

\section{Results}

Aerobic gymnastics athletes hamstring muscles elasticity were lower before Pilates exercises, after Pilates exercises hamstring muscles elasticity changed significant after 7 and 14 weeks. Aerobic gymnastics athlete's trunk mobility was within the norms in Sit and reach test before Pilate's exercises, after Pilates exercises trunk mobility changed significant after 7 and 14 weeks and between 7 and 14 weeks testing (Figure 2-8).

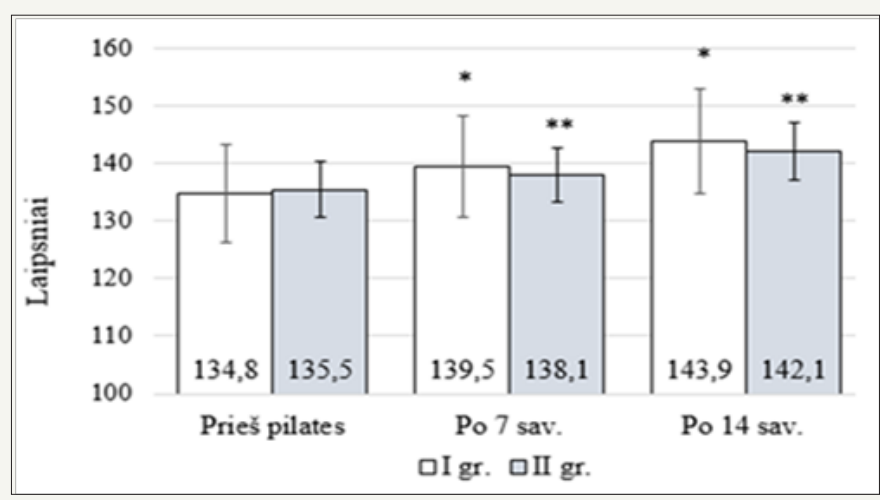

Figure 2: Results of active right knee extension in groups.

${ }^{*}$-p $<0.05$ : Comparing results in I group before and after Pilates exercises; **-p<0.05: Comparing results in II group before and after the study

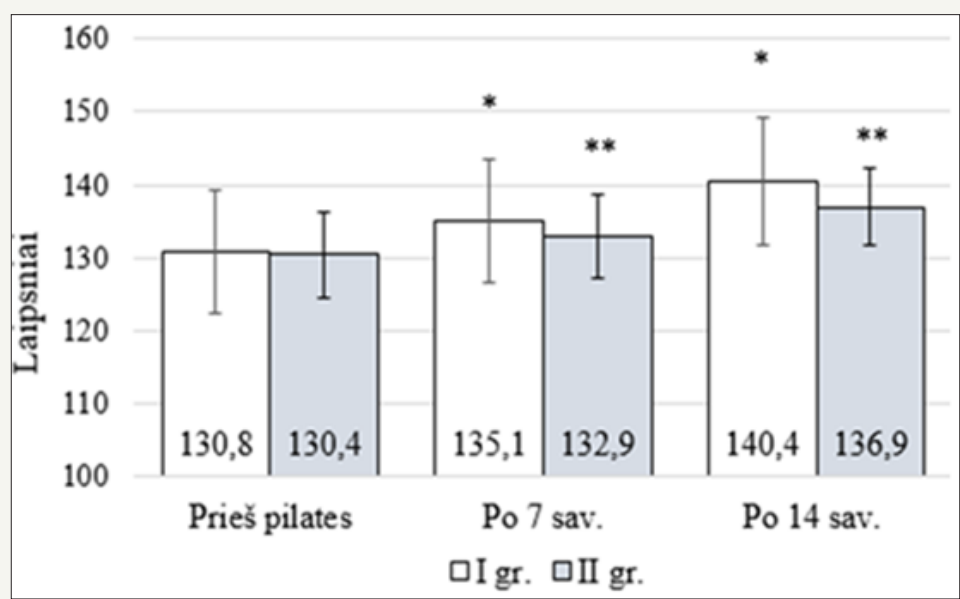

Figure 3: Results of active left knee extension in groups.

${ }^{*}$-p $<0.05$ : Comparing results in I group before and after Pilates exercises; **-p<0.05: Comparing results in II group before and after the study

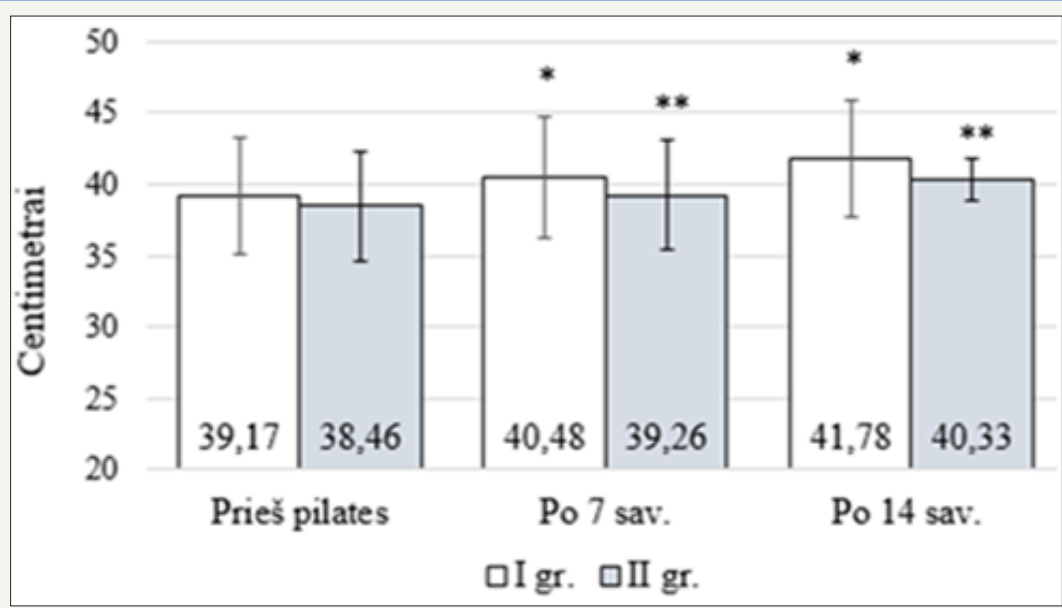

Figure 4: Results of sit and reach test.

${ }^{*}$-p $<0.05$ : Comparing results in I group before and after Pilates exercises; ${ }^{* *}$-p $<0.05$ : Comparing results in II group before and after the study 


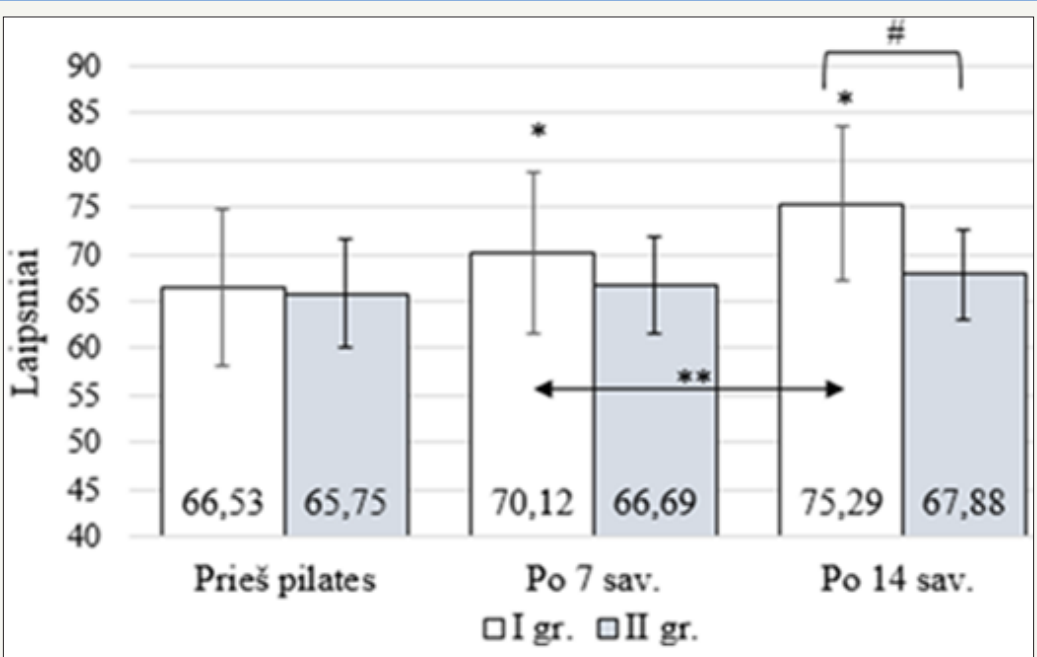

Figure 5: Results of active trunk flexion.

${ }^{*}$-p $<0.05$ : Comparing results in I group before and after Pilates exercises; ${ }^{* *}-\mathrm{p}<0.05$ : Comparing results in II group before and after the study

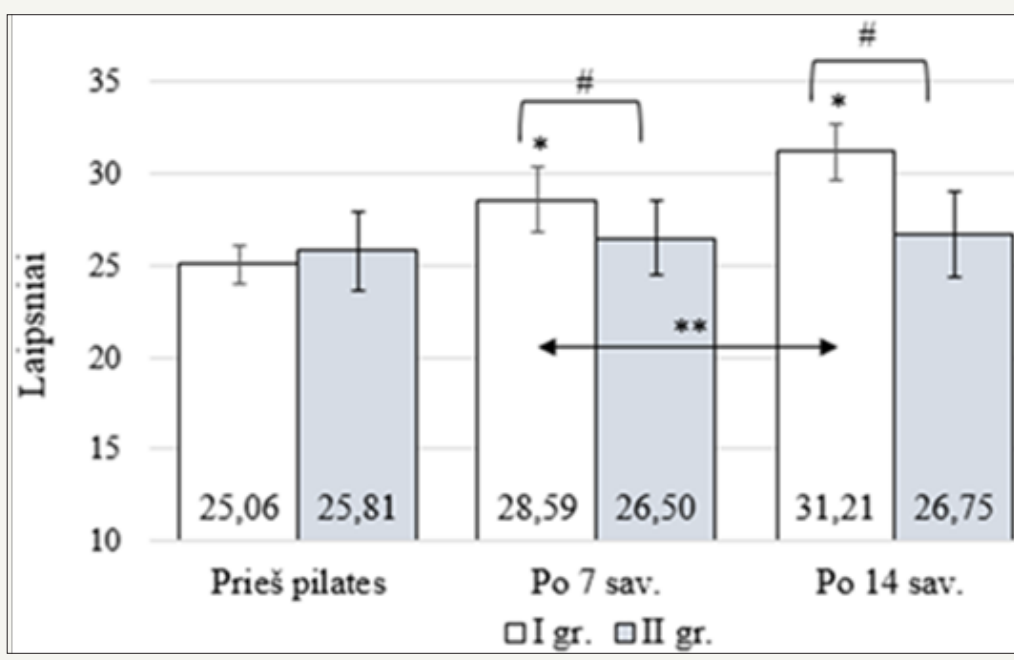

Figure 6: Results of active trunk extension.

${ }^{*}$-p $<0.05$ : Comparing results in I group before and after Pilates exercises; ${ }^{* *}-\mathrm{p}<0.05$ : Comparing results in II group before and after the study

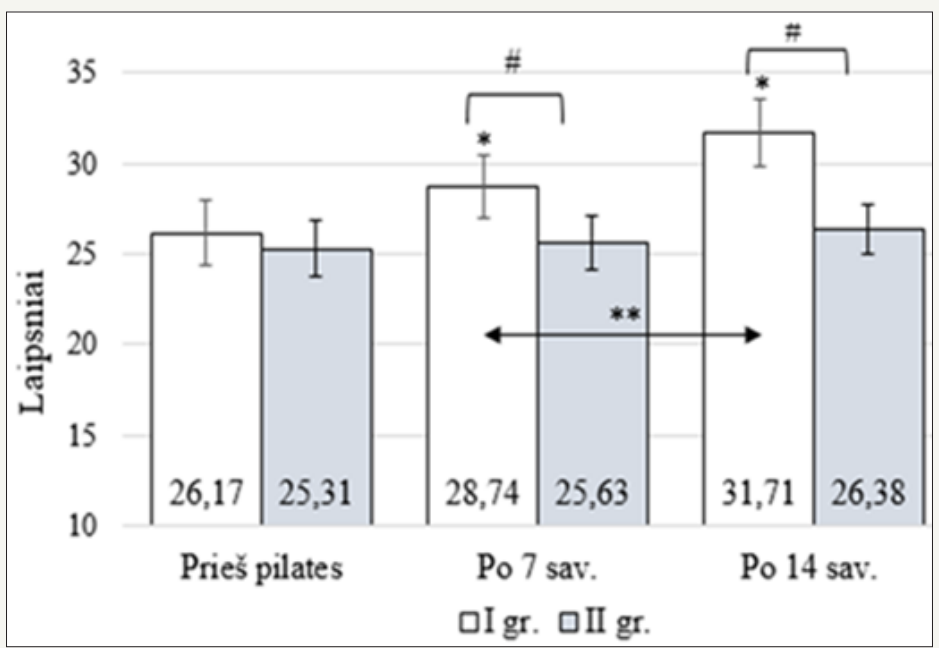

Figure 7: Results of active trunk lateral flexion to right.

${ }^{*}$-p $<0.05$ : Comparing results in I group before and after Pilates exercises; ${ }^{* *}-\mathrm{p}<0.05$ : Comparing results in I group between II and III testing; $\#-\mathrm{p}<0.05$ : Comparing results between I and II groups after Pilates exercises 


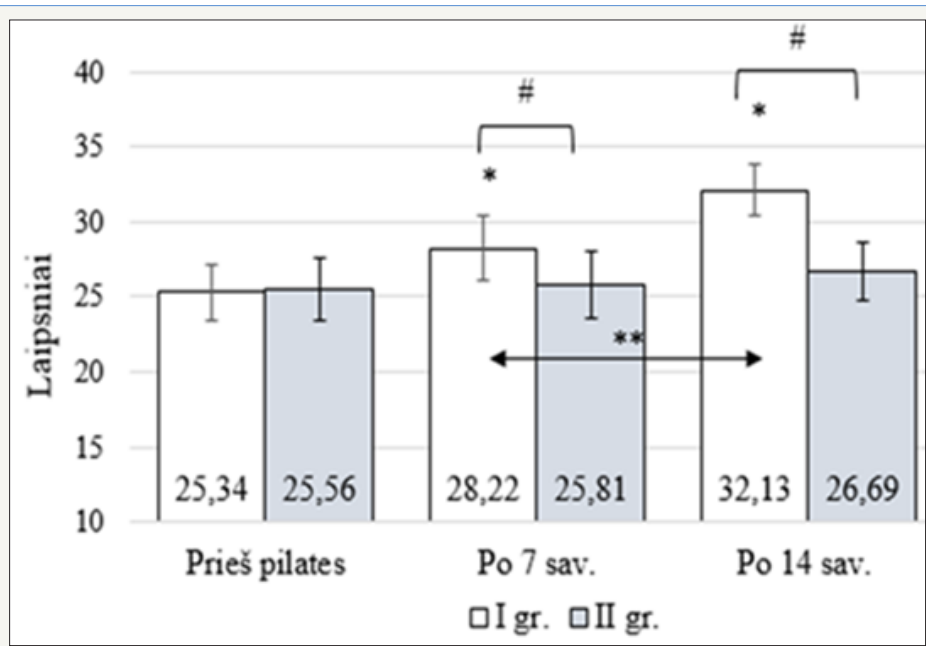

Figure 8: Results of active trunk lateral flexion to left.

${ }^{*}$-p<0.05: Comparing results in I group before and after Pilates exercises; ${ }^{* *}$-p $<0.05$ : Comparing results in I group between II and III testing;

$\#-p<0.05$ : Comparing results between I and II groups after Pilates exercises

\section{Conclusions}

1. Aerobic gymnastics athletes hamstring muscles elasticity were lower before Pilates exercises, after Pilates exercises hamstring muscles elasticity changed significant after 7 and 14 weeks.

2. Aerobic gymnastics athletes trunk mobility was within the norms before Pilates exercises, after Pilates exercises trunk mobility changed significant after 7 and 14 weeks and between 7 and 14 weeks testing.

3. Before Pilates exercises aerobic gymnastics athletes hamstring muscles elasticity and trunk mobility did not differ between the groups. After Pilates exercises aerobic gymnastics athletes hamstrings muscles elasticity did not differ significant between the groups, trunk flection differ significant between the groups after 14 weeks, while extension and lateral flection to right and left differ significant between the groups after 7 and 14 weeks.

\section{References}

1. Critchley DJ, Pierson Z, Battersby G (2011) Effect of pilates mat exercises and conventional exercise programmes on transversus abdominis and obliquus internus abdominis activity: pilot randomised trial. Man Ther 16(2): 183-189.

2. Amorim CF, Serrão FV, Pereira VS, Santiago PR, Benze BG, et al. (2011) Variations in dynamic knee valgus and gluteus medius onset timing in non-athletic females related to hormonal changes during the menstrual cycle. Knee 18(4): 224-230.

3. Di Lorenzo CE (2011) Pilates: what is it? Should it be used in rehabilitation? Sports Health 3(4): 352-361.

4. Alves CR, Borelli MT, Paineli Vde S, Azevedo Rde A, Borelli CC (2015) Development of a specific anaerobic field test for aerobic gymnastics. PLoS One 10(4): e0123115.
Creative Commons Attribution 4.0 International License

For possible submissions Click Here

\section{Submit Article}

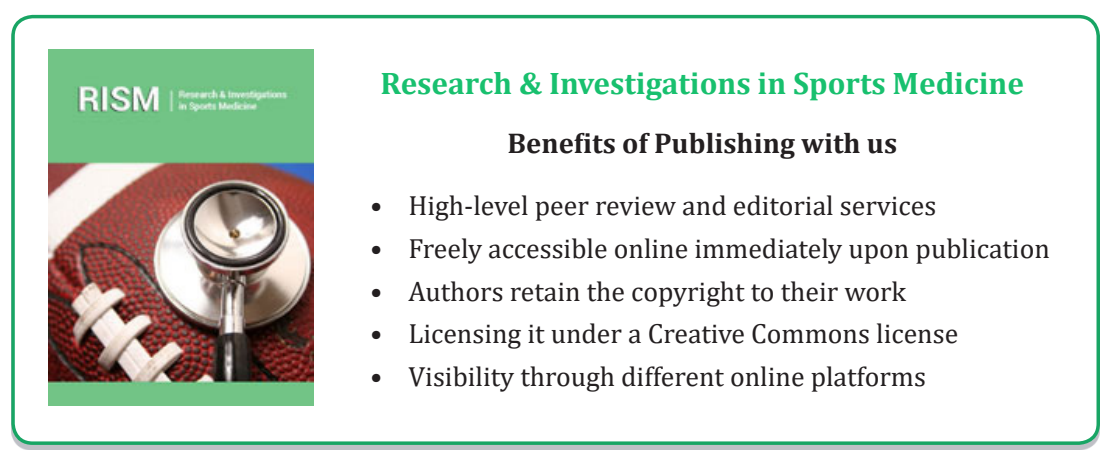

